\title{
Hantavirus: Su distribución geográfica entre los roedores silvestres de Chile
}

\author{
CARLOS PAVLETIC B. M.V. ${ }^{1}$
}

\author{
HANTAVIRUS: GEOGRAFICAL DISTRIBUTION AMONG THE WILD \\ RODENTS IN CHILE
}

\begin{abstract}
Since the first case of SPH was detected in 1995, wild rodent have been under surveillance in order to identify the hantavirus reservoir, its geographic distribution and its main habitat. During 1998 and 1999 seroprevalence studies were carried out in diverse sites, specially in rural areas, from the Metropolitan to Aysen regions. Oligoryzomys longicaudatus has been identified as the reservoir of Andes virus capable to infect either human beings or other rodent that coexist with in the same habitat. The putative reservoir showed a wide geographic distribution in the studied area but its highest population density was found in the southern region. Other four species of wild rodent were found seropositive to hantavirus in the study. That situation can be explained because the ability of the putative reservoir to infect coexistent rodents of the ensemble. Nevertheless, Abrothrix longipilis was found carrier of hantavirus by PCR technique and further investigations are necessary to clarify its role in the transmission chain of hantavirus.
\end{abstract}

Key words: Hantavirus, Rodents, Reservoir.

\begin{abstract}
ANTECEDENTES
La confirmación de la circulación de hantavirus en las poblaciones de roedores silvestres de Chile, ocurrida el año 1995, a través de la identificación del primer caso humano del síndrome pulmonar por hantavirus (SPH) en la zona de Segundo Corral, X Región del país, significó la puesta en marcha de un amplio sistema de control y prevención de esta zoonosis por parte del sistema de salud. Los conocimientos obtenidos a partir de las investigaciones realizadas del primer brote de esta enfermedad ocurrido en los E.U.A. el año 1993, así como en los

brotes descritos en otros países de América, permitieron sentar en forma temprana las bases de un sistema eficiente de vigilancia, prevención y control de la enfermedad.

$\mathrm{Al}$ igual que en el síndrome renal provocado por hantavirus, patología endémica en Asia y Europa, las investigaciones de los brotes del SPH permitieron establecer que el reservorio de las variedades de hantavirus que lo provocan son, invariablemente, roedores silvestres. ${ }^{1-3}$ Este hecho es de trascendental importancia en el estudio de la epidemiología de esta zoonosis, como en su prevención y control, considerando que
\end{abstract}

\footnotetext{
1 Departamento de Programas sobre el Ambiente, División de Salud Ambiental. Ministerio de Salud de Chile.
} 
los roedores son los mamíferos que presentan el mayor número de especies, se encuentran presente en prácticamente todos los hábitats, tienen una gran capacidad reproductiva y de adaptación, ${ }^{4}$ por lo que su presencia constituye un factor ambiental de riesgo para la presentación de casos de SPH.

En esta perspectiva, el conocimiento de la epidemiología del virus en la naturaleza resulta de trascendental importancia para la adopción de medidas de prevención y control. Estas investigaciones tienen como objetivo, en primer término, identificar la(o las) especie(s) de roedor(es) que en el país actúa(n) como reservorio del virus. Identificado el reservorio es necesario determinar la distribución geográfica de éste, así como la distribución geográfica del virus en las poblaciones de roedores. Además de lo anterior, la determinación de los hábitats de los reservorios y el virus y la distribución de éste dentro de los diferentes estratos de individuos dentro de las poblaciones, permite establecer los mecanismos más probables de transmisión. Por otra parte, teniendo en cuenta la influencia de los factores ambientales sobre las poblaciones de roedores y posiblemente sobre las tasas de prevalencia de la infección intrapoblacional, se requieren estudios de dinámica poblacional que posibiliten correlacionar los cambios ambientales tales como pluviosidad, temperaturas, oferta natural de alimentos y otros, con la densidad en las poblaciones de roedores y las tasas de prevalencia de infección por hantavirus en éstas. ${ }^{5}$

La herramienta para obtener los conocimientos epidemiológicos anteriormente señalados es los estudios de reservorios, actividad que mediante la aplicación de una metodología específica permite la captura de roedores vivos, en un hábitat conocido, para su posterior identificación taxonómica, estimación de la densidad poblacional puntual y análisis virológico.

\section{Ecología y epidemiología del hantavirus en los reservorios}

La evidencia que los roedores silvestres son los reservorios del hantavirus en la naturaleza y la amplia distribución que éstos tienen en todos los hábitats, supone que estamos frente a una enfermedad que potencialmente se presentará en cualquier lugar donde los roedores silvestres existan. Por otra parte, dado que aparentemente el virus no produce enfermedad ni efectos adversos en los reservorios, y es eliminado en sus excreciones por largos períodos, se puede mantener en estas poblaciones y transmitir permanentemente en ellas, de forma horizontal. La transmisión se produce entre los roedores principalmente a través de la vía respiratoria -al igual que en los humanos- por la estrecha convivencia en madrigueras altamente contaminadas con fecas y orinas. La mordedura es otra forma de transmisión del virus entre los roedores. Estas vías de transmisión, al parecer, explicarían el hecho observado que se encuentra una mayor seroprevalencia entre los roedores adultos que en los juveniles. La especificidad que cada virus presenta con su reservorio determina que cada virus tenga un solo roedor que actúa como reservorio. En esta característica radica la importancia de identificar claramente las especies reservorios, lo que permite determinar la importancia epidemiológica de cada especie en la transmisión de la enfermedad.

La variación en la densidad de las poblaciones de roedores ha sido identificada como un factor de gran relevancia en la presentación de casos de síndromes asociados a hantavirus. Estos cambios poblacionales se ven influenciados por muchos y muy diversos factores y pueden variar a través del tiempo por razones de estacionalidad, cambios climáticos, variación en la oferta de alimentos, presencia de predadores u otros. Así, en Chile se estima que el florecimiento de la quila (Chusquea quila), así como otros representantes del género, hecho que ocurre cada veinte años, tiene un importante efecto sobre el crecimiento de las poblaciones de roedores silvestres, a causa de la importante cantidad de semillas que produce esta planta y que sirve de alimento a los roedores. Este fenómeno ocurrido en los años recientes en la zona sur puede ser una causa del brote epidémico ocurrido en la zona.

Por otra parte, la presentación de casos se encuentra fuertemente ligada a personas que desarrollan sus actividades o viven en zonas rurales, en las que se presentan deficiencias de saneamiento y especialmente de estructuras en sus 
viviendas. Estos factores facilitan el contacto directo con roedores o sus excreciones, en cantidades suficientes para provocar el cuadro. Por razones similares, otro grupo expuesto es el de las personas que realizan actividades de camping o excursiones sin tomar las precauciones necesarias para evitar el contacto riesgoso con roedores y sus excretas.

Como se puede observar, la multiplicidad de factores ambientales que inciden en la presentación del SPH, requiere continuar los estudios que permitan conocer con mayor exactitud las vías de circulación del virus en la naturaleza, así como los factores de mayor relevancia en su perpetuación y transmisión. El conocimiento más acabado de estos antecedentes permitirá, sin duda, orientar en mejor forma las medidas de prevención y control de la enfermedad.

\section{ESTUDIOS DE RESERVORIOS EN CHILE}

La estrategia implementada por el Ministerio de Salud, en orden a desarrollar los estudios de reservorios necesarios para investigar la epidemiología del hantavirus en los roedores fue el establecer convenios de colaboración con entidades especializadas en el estudio de la fauna silvestre. En esta perspectiva se establecieron contactos, especialmente con las universidades del país, encontrándose en estas entidades académicas, equipos de especialistas de reconocida experiencia nacional e internacional en el estudio de los roedores y su ecología. Basados en esta experiencia, complementada con el importante aporte en el área de la bioseguridad y las técnicas de monitoreo y estudio de hantavirus en terreno, obtenidos a través de la colaboración internacional, desde el CDC de los E.U.A. y del Instituto de Investigación Enfermedades Virales Humanas Julio Maiztegui, Pergamino, Argentina, se establecieron los equipos de trabajo que permitieron los estudios de reservorios requeridos.

\section{Estudio preliminar}

Establecida, esta modalidad de trabajo colaborativo con las universidades ante la aparición de los dos primeros casos en Chile, los primeros estudios de reservorios realizados en el país fueron proyectados por los Servicios de Salud de Osorno y Llanquihue-Chiloé- Palena (Llanchipal) y ejecutados por el Instituto de Ecología y Evolución de la Universidad Austral de Chile, Valdivia, en el año 1996. Las actividades de captura de roedores se desarrollaron en las localidad de Segundo Corral, lugar en que se originó el primer caso de la enfermedad en Chile, y que está ubicada en la frontera con la República Argentina, vecina al pueblo de El Bolsón, escenario de el primer brote de la enfermedad en 1995 en la zona sur del continente. Se realizaron estudios también en la zona de Chiloé, origen del segundo caso de la enfermedad confirmada en el país, y en la zona cordillerana del paso fronterizo Puyehue, en la jurisdicción del Servicio de Salud Osorno.

Estos estudios se desarrollaron entre los meses de mayo y diciembre de 1996, en diferentes áreas de las zonas seleccionadas y de acuerdo a las posibilidades de operatividad que ofrecían las condiciones climáticas de la zona. Así, los resultados de capturas en las diferentes áreas arrojaron en números totales, 50, 46, y 30 roedores capturados en las zonas de Puyehue, Chiloé y Segundo Corral respectivamente, totalizando 127 capturas en el estudio. La diversidad de especies capturadas es relativamente escasa y se encuentra representada por sólo cuatro especies, todas ellas silvestres. Del total de roedores capturados el 75\% correspondió a la especie Abrothrix olivaceus, $16 \%$ a Oligoryzomys longicaudatus, $7 \%$ a Abrothrix longipilis у $2 \%$ a Geoxus valdivianus (Figura 1).

Si bien la composición de las poblaciones de roedores silvestres varía de acuerdo a diversos factores ambientales como son la estacionalidad, el clima, la disponibilidad de alimentos, el hábitat, los predadores y otros, en las áreas estudiadas presentaron una relativa uniformidad en relación a la composición de sus poblaciones, predominando en todas ellas la especie A. olivaceus con un peso de entre 57 y $93 \%$ de los individuos, compartiendo su hábitat principalmente con $O$. longicaudatus que alcanza la segunda densidad en casi todas las áreas. En menor medida y frecuencia se observaron A. longipilis y esporádicamente otras especies silvestres. ${ }^{6}$

En los estudios serológicos de los roedores 


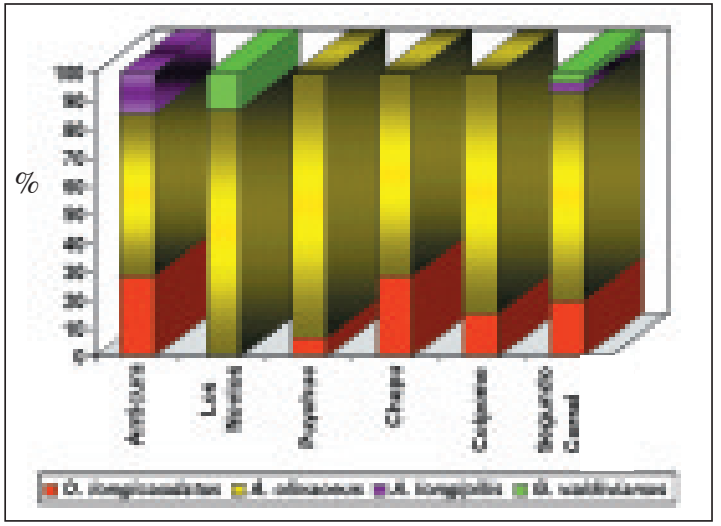

Figura 1 . Composición de población de roedores por especie y localidad. X Región, Chile 1996.

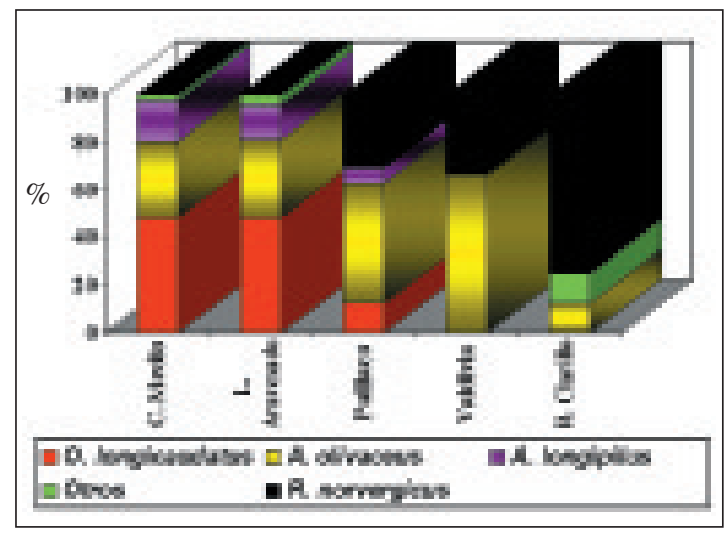

Figura 2. Composición de poblaciones de roedores por especies y localidad en zonas de Aysén (CM, LA), Valdivia (P, V) y Región Metropolitana (RC).

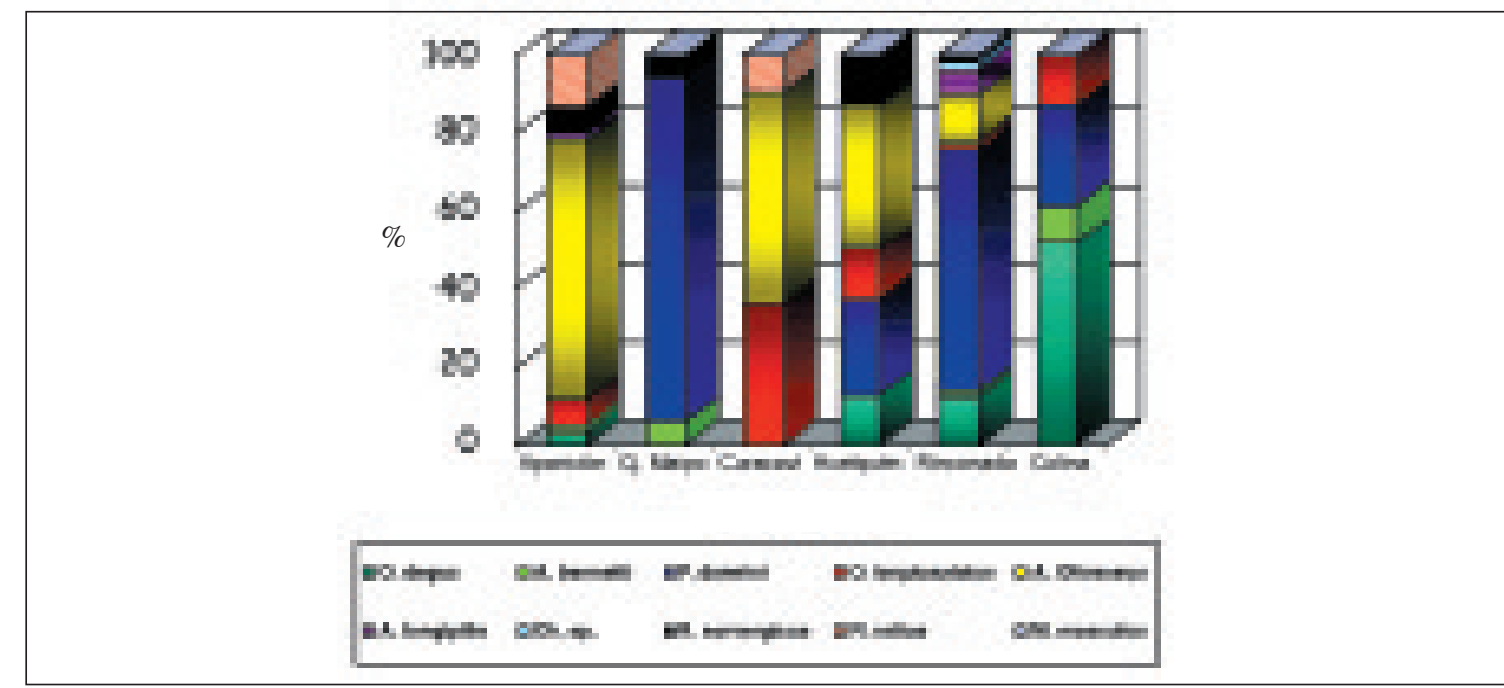

Figura 3. Composición de poblaciones de roedores por especies y localidad. Región Metropolitana Chile 1998.

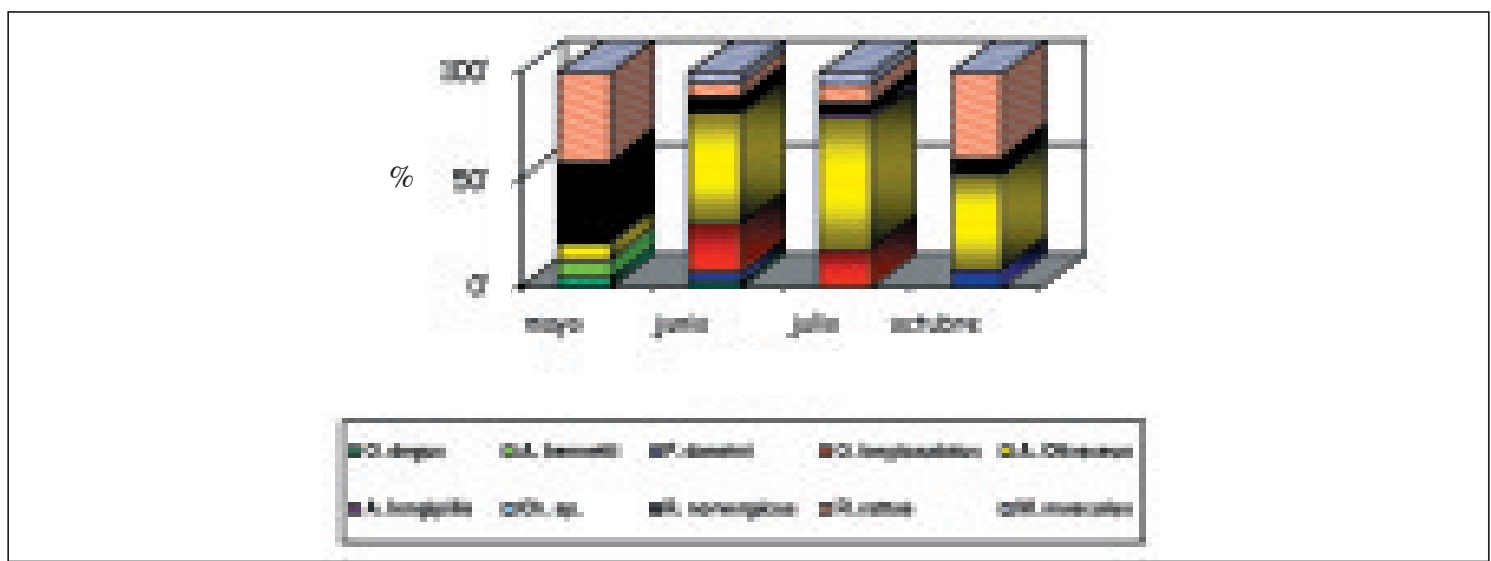

Figura 4. Composición de poblaciones de roedores por especie y mes. Picarquin, VI Región Chile 1998. 
capturados, los que fueron realizados por el Instituto Dr. Carlos Malbrán de Buenos Aires, Argentina, se encontraron positivos sólo dos ejemplares de la especie A. olivaceus, capturados en el área de Puyehue. Esto corresponde a 2,2\% de los A. olivaceus examinados y a $1,7 \%$ del total de los roedores examinados en el estudio. $\mathrm{Da}-$ das las limitaciones con que se realizaron estos primeros estudios, debido a la falta de conocimientos de las técnicas de estudios de hantavirus en terreno y la inexistencia de laboratorios especializados en su diagnóstico en el país, estos resultados deben ser considerados preliminares.

\section{Estudios desarrollados con la colaboración internacional}

Durante el año 1997, con la colaboración de la OPS, el CDC de Atlanta, E.U.A. y del Instituto de Investigación de Enfermedades Virales Julio Maiztegui, Pergamino, Argentina, y la participación de los Servicios de Salud y el Ministerio de Salud, se efectuaron nuevos estudios, los que estuvieron orientados principalmente, a conocer la presencia de reservorios del virus en zonas endémicas y su comparación con áreas sin casos. En este contexto se estudió la zona de Coyhaique, la que presentó casos en forma epidémica durante ese año. La presentación de brotes familiares en las localidades de Cisne Medio y Lago Atravesado en la Región de Aysén, determinaron su elección para desarrollar estudios de reservorios en los domicilios y hábitat circundante a estos brotes. Como áreas de comparación se realizaron estudios en la provincia de Valdivia y Región Metropolitana (Figura 2).

Los estudios realizados en las localidades de Cisne Medio y Lago Atravesado en la Región de Aysén se orientaron a comprobar la circulación de hantavirus en las poblaciones de roedores silvestres presentes en las viviendas en que se produjeron los brotes familiares de la enfermedad y en el hábitat circundante a ellas, el que incluyó dos viviendas a una distancia de 300 y 800 metros de la vivienda afectada, como controles cercano y lejano respectivamente. En ambos casos las viviendas se encontraban insertas en ambientes naturales poco intervenidos por el hombre, con abundante bosque nativo y su flora acompañante, con altas precipitaciones y presencia de ríos o lagos.

En el sector de Cisne Medio se desplegaron aproximadamente 236 trampas divididas en partes iguales en las tres viviendas en estudio, las que se mantuvieron por una noche. Las trampas se ubicaron, en números iguales, dentro de las viviendas, en el perímetro de ellas y en los hábitats naturales más cercanos. En este sector se obtuvieron 89 capturas lo que representa un $38 \%$ de éxito de captura, cifra que indica claramente la considerable cantidad de roedores existentes en el área en el momento del estudio. Los resultados obtenidos mostraron que en la casa de los enfermos y sus alrededores se capturaron mayor número de roedores que en las casas vecinas tomadas como controles. Por otra parte, desde el punto de vista de la composición de la población capturada, se pudo establecer que en el área sólo existen roedores silvestres, y que en el momento del estudio, la especie más numerosa era $O$. longicaudatus con $47 \%$ de los individuos capturados, seguida por A. olivaceus (33\%) y A. longipilis (16\%).

En el sector de Lago Atravesado, las condiciones ecológicas son similares a las descritas anteriormente, marcando la diferencia, desde el punto de vista ambiental, la presencia del lago existente en la área y las condiciones de las tres viviendas seleccionadas, las que se encuentran en mejor estado de mantención que las de Cisne Medio. Siguiendo el mismo criterio anterior, se desplegaron 333 trampas en dos noches de capturas, en números similares en cada vivienda estudiada. En esta área se obtuvo 49\% de éxito de captura es decir, de cada dos trampas colocadas, una resultó con captura. La composición de la población de roedores capturados mantuvo la misma estructura que la observada en Cisne Medio, lo que demuestra que en esa zona de la Región de Aysén, y en el momento que se realizó el estudio, predominaba la especie $O$. longicaudatus, acompañada principalmente por $A$. olivaceus y A. longipilis. El estudio mostró claramente que en esa área existía, en el momento del estudio, un marcado aumento de la densidad poblacional de roedores silvestres que, como se ha demostrado en otras situaciones a través del mundo, es un factor determinante en la presentación de casos de hantavirus. Esta causa efecto 
Hantavirus: Su distribución geográfica entre los roedores silvestres de Chile - C. Pavletic B.

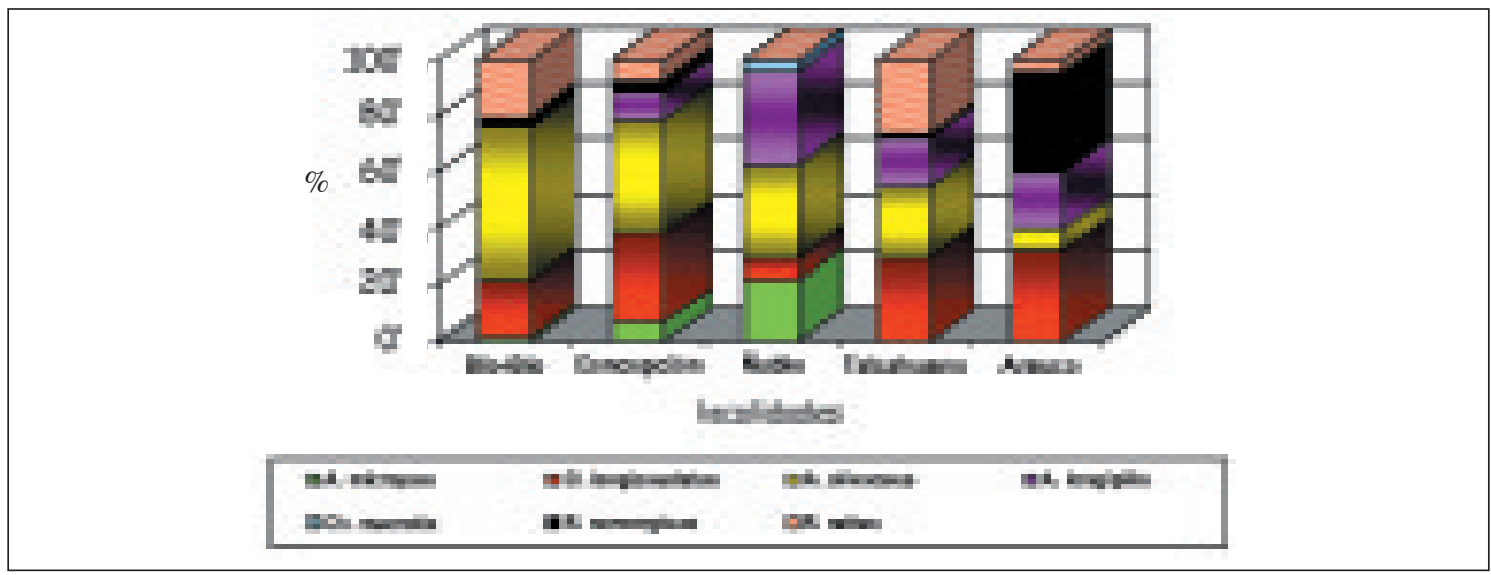

Figura 5. Composición de poblaciones de roedores por especie y localidad. VIII Región, Chile 1998.

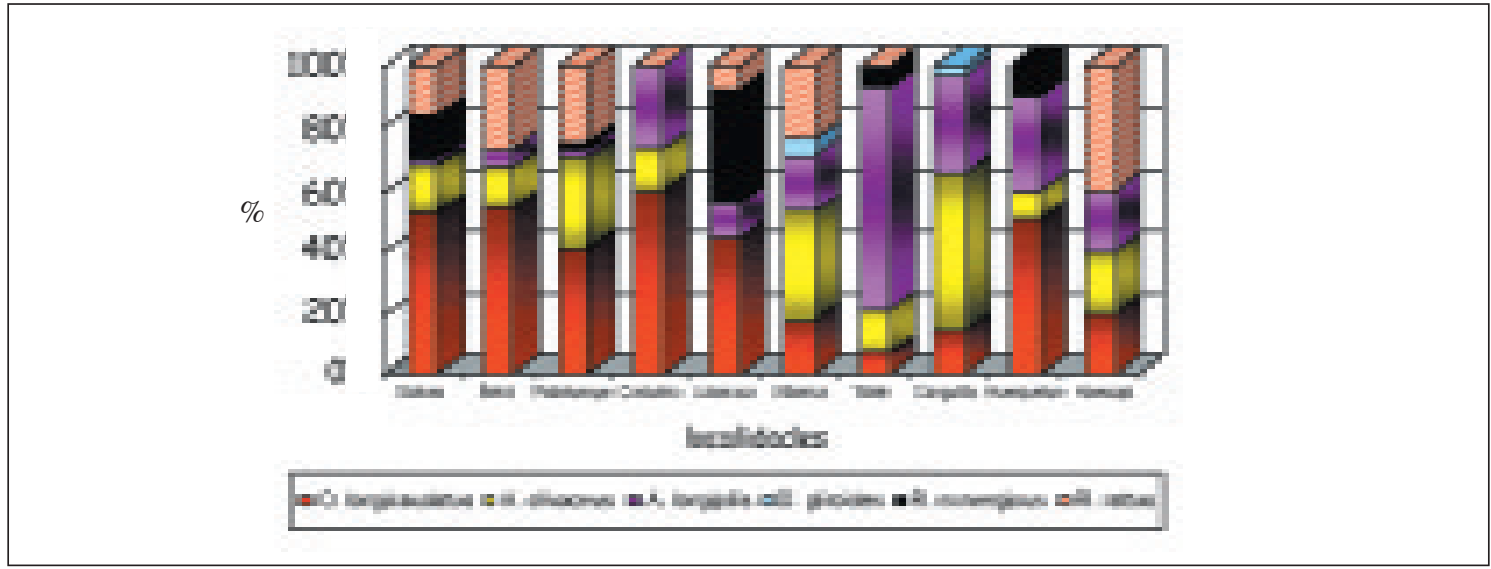

Figura 6. Composición de poblaciones de roedores por especie y localidad. IX Región, Chile 1998-1999.

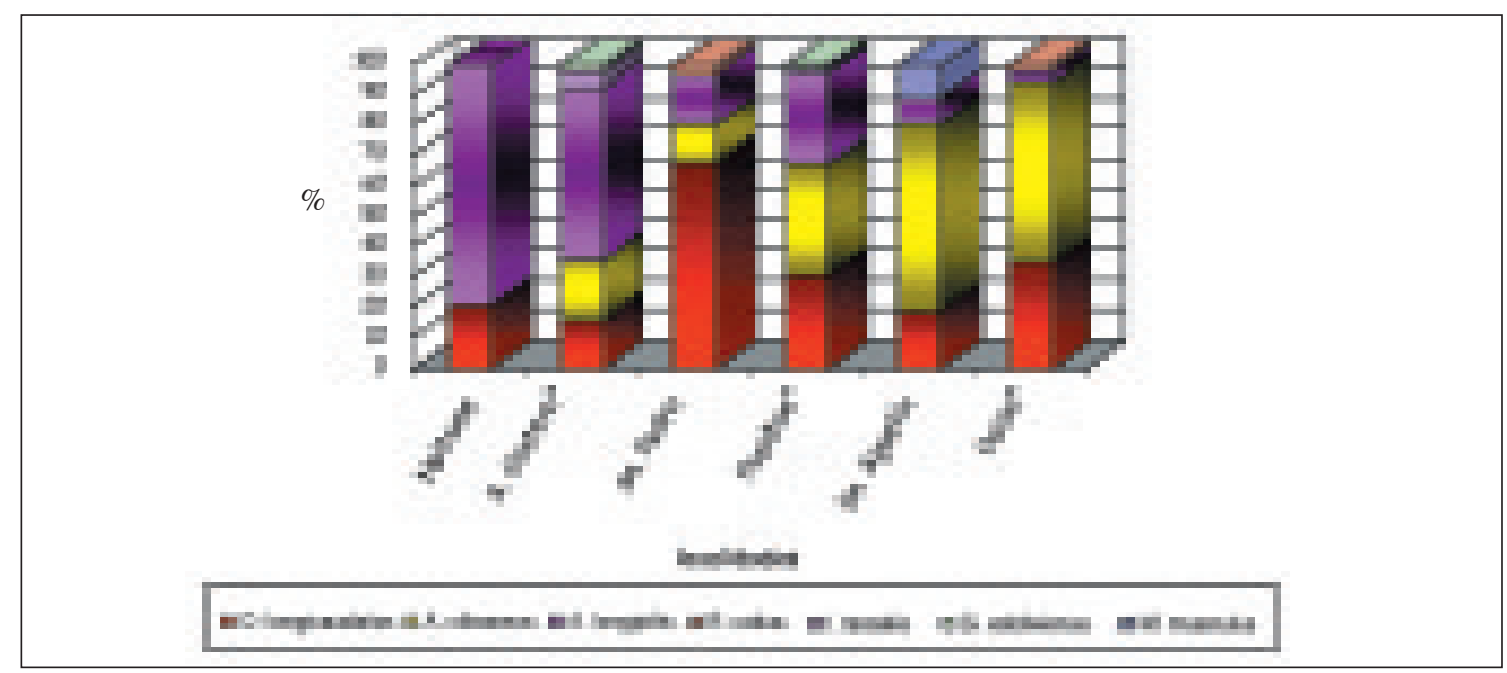

Figura 7. Composición de poblaciones de roedores por especies y localidad. X Región, Chile 1998. 
Hantavirus: Su distribución geográfica entre los roedores silvestres de Chile - C. Pavletic B.

es aún más manifiesta si consideramos que los resultados de laboratorio realizados en el CDC, nos indican que prácticamente $10 \%$ de los roedores capturados en este estudio en las zonas de Aysén, resultó positivos a hantavirus. De éstos la especie $O$. longicaudatus presentó $13 \%$ de positividad, A. olivaceus $8 \%$ y A. longipilis $3 \%$.

De acuerdo a los análisis genéticos realizados a los virus aislados de estas especies en este estudio, todos ellos correspondieron a la variedad de virus Andes. Este antecedente, a la luz de los conocimientos actuales, permite afirmar que, al igual que en la zona sur de Argentina, la especie reservorio en el área estudiada es $O$. longicaudatus, a partir de la cual se han infectado las demás especies, las que no tendrían calidad de reservorio.

A diferencia de la situación encontrada en la jurisdicción de Aysén, los estudios realizados en el mismo período, y por el mismo equipo, en la zona de Valdivia y Región Metropolitana, demostraron claras diferencias en cuanto a la densidad y composición de las poblaciones, de acuerdo a las especies capturadas.

En la jurisdicción de Valdivia se realizaron capturas en el valle central, área caracterizada por un ecosistema altamente intervenido, con escasa presencia de hábitat natural por el intenso uso productivo y habitacional. Estas características se reflejan claramente en el resultado de las capturas, que muestran la existencia de poblaciones de roedores con densidades normales, la aparición de una importante proporción de roedores antropofílicos propios de los ambientes con una alta presencia humana y el cambio en la composición de las poblaciones de roedores silvestres. Así, los éxitos de captura en las dos zona de estudio alcanzaron a 11 y $1,5 \%$ respectivamente. En estas áreas A. olivaceus es la especie silvestre más numerosa, con escasa participación de otras especies silvestres y aparecen los roedores comensales que alcanzan aproximadamente al 30\% de las capturas. En esta zona no se detectaron roedores infectados con hantavirus en este estudio.

En tanto, el estudio realizado en la Región Metropolitana se desarrolló en la Reserva Nacional Río Clarillo. El número de roedores capturados en esta área fue extremadamente reducido, sólo 8 ejemplares de los cuales $80 \%$ fue- ron roedores sinantrópicos, lo que llama la atención por ser ésta un área de flora nativa con una moderada intervención. Estos resultados, se estima, estuvieron fuertemente influenciados por las condiciones climatológicas que afectaron esta región durante el período de invierno 1996 y verano de 1997. Este período de aguda sequía tuvo una influencia negativa sobre la población de roedores silvestres de la zona, encontrándose una escasa población de ellos en este estudio. Como era de suponer por la composición de especies de la muestra obtenida, no se encontraron roedores infectados con hantavirus en esta zona. ${ }^{7}$

\section{Estudios de reservorios regionales}

La rápida respuesta del sector salud ante la emergencia del hantavirus quedó demostrada, entre otras iniciativas, en el establecimiento de laboratorios de diagnóstico de la enfermedad y la implementación de los equipos de terreno y la capacitación de técnica de personal para el estudio y control ambiental de la enfermedad. Este fortalecimiento del sector permitió desarrollar estudios de reservorio regionales orientados a establecer las áreas de riesgo a través de conocer con mayor precisión la distribución del virus entre las poblaciones de reservorio.

Así, se definió la necesidad de realizar estudios de reservorios desde la Región Metropolitana al sur con énfasis en aquellas regiones y áreas que presentaban mayor riesgo teórico, con base en sus características ecológicas propicias para el desarrollo de los roedores. En esta perspectiva, durante 1998 se desarrollaron estudios de reservorios en las regiones de riesgo, los que fueron desarrollados en forma conjunta por universidades locales y los Servicios de Salud.

\section{Región Metropolitana}

Los estudios en la Región Metropolitana se realizaron entre abril y diciembre del año 1998. Considerando el alto grado de intervención que presentan los predios de la región, estos representan pobremente los ambientes naturales originales, por lo que se seleccionaron seis sitios a los alrededores de Santiago utilizando como criterio su ubicación en los distintos ambientes representados en la región y la restricción de ac- 
ceso a ellos.

Las capturas totales obtenidas en la región fueron 196 roedores, entre las que se registraron 7 especies silvestres y 3 especies sinantrópicas. Los rendimientos de las capturas en los diferentes sitios mostraron un rango entre $1,4 \mathrm{y}$ $5,3 \%$, los que se encuentran dentro de los índices de capturas normales. Si bien las composiciones de las poblaciones difieren de un sitio a otro (Figura 3), así como también se evidenciaron variaciones mensuales en el número de capturas, ellas se explican por los efectos climáticos naturales y las diferencias de los microhábitats de cada sector muestreado.

Las especies más frecuentes en la región fueron Phillotys darwini (31\%), A. olivaceus (29\%) y Octodon degus (13\%). El reservorio del hantavirus, O. longicaudatus, representó el 7\% de las capturas de la región y fue capturado en cinco de los sitios muestreados aunque en general presentó una baja densidad.

Los estudios serológicos detectaron un $O$. longicaudatus y un $P$. darwini seropositivo en el área de Rinconada de Maipú, y un $P$. darwini en el Cajón del Maipo, lo que demuestra que existe circulación del hantavirus en las poblaciones de roedores de la región. Posteriores investigaciones deberán dilucidar si $P$. darwini tiene algún rol en la transmisión del virus. ${ }^{8}$

\section{Región del Libertador B. O' Higgins}

Con el fin de conocer y controlar los riesgos relacionados con el hantavirus y prevenir la presentación de casos de SPH entre los participantes al Jamboree Mundial organizado por la Asociación de Scouts de Chile en diciembre de 1998, se desarrolló un estudio de reservorio en el fundo Picarquin, sede del encuentro. Este estudio consideró la captura de roedores en áreas representativas de los hábitats del predio, en diferentes épocas del año, entre mayo y noviembre de 1998.

Un total de 159 roedores fueron capturados en los sitios de trampeo seleccionados en el área y en las diferentes épocas del año. Seis especies silvestres y 3 sinantrópicas estuvieron representadas en las capturas. Se observaron claras variaciones en la composición de las poblaciones capturadas en los diferentes meses del año. Los roedores silvestres aumentaron fuertemente su densidad en los meses de junio y julio, a diferencia de mayo y octubre en que predominaron los roedores introducidos. Los rendimientos de captura, normales para esta área, mostraron un rango entre 1 y $8 \%$, siendo mayores en los meses de invierno donde predominaron las especies silvestres.

Entre los roedores silvestres capturados, A. olivaceus y O. longicaudatus presentaron la mayor abundancia con 48 y $14 \%$ del total de las capturas respectivamente, en tanto los roedores sinantrópicos alcanzaron al 33\% de ellas, aunque con marcadas diferencias estacionales en su composición (Figura 4).

La circulación de hantavirus en el área investigada se evidenció en la detección de 5 ejemplares de $O$. longicaudatus seropositivos, lo que representa el $23 \%$ de positividad dentro de la especie y $3,2 \%$ del total de las capturas.

\section{Región del Bío Bío}

En la Región de Bío Bío se estudiaron cinco áreas representativas de los ecosistemas tanto cordilleranos como costeros existentes en ella. Se consideraron, entre éstos, sitios con registro de casos con SPH confirmado. En las zonas de cordillera seleccionadas, la vegetación predominante correspondió a bosque preandino con diferentes grados de alteración; en cambio en las zonas costeras, especialmente Arauco, la vegetación está representada por especies arbóreas introducidas como Pinus radiata y Eucalyptus globulus.

Un total de 326 roedores fueron capturados en las áreas estudiadas en esta región entre los meses de mayo y junio de 1998. Cinco especies silvestres y dos sinantrópicas estuvieron representadas entre los individuos capturados. Las especies más frecuentemente capturadas correspondieron a $A$. olivaceus $(36 \%), O$. longicaudatus (26\%), y A. longipilis (14\%). Las dos primeras especies, además de ser las más abundantes, aparecieron como las de mayor distribución en la región, ya que fueron capturadas en prácticamente todos los sitios de trampeo (Figura 5).

En total 5 ejemplares resultaron con serología positiva a hantavirus en la región, estos correspondieron a $2 \mathrm{~A}$. longipilis provenientes del área de Nuble y a 2 O. longicaudatus y un $A$. 
micropus, capturados en la zona de Bío Bío. El porcentaje de positividad total de la muestra de la región fue de $1,5 \%$ y dentro de las especies positivas fue de $4,5,2,5$ y $5,2 \%$ respectivamente. Todos los roedores seropositivos fueron capturados en los hábitats cordilleranos. ${ }^{10}$

\section{Región de la Araucanía}

Diez sitios distribuidos en los diferentes ambientes de la región fueron seleccionados para realizar capturas, las que se desarrollaron entre agosto de 1998 y diciembre de 1999. Un total de 261 roedores fueron capturados en el estudio. Cinco especies silvestres y 2 sinantrópicas estuvieron representadas en las capturas. De las especies silvestres $O$. longicaudatus presentó la mayor frecuencia de captura (41\%) del total de la muestra, seguido de A. olivaceus (23\%) y A. longipilis (14\%); estas tres especies aparecieron como las más frecuentes en la región encontrándose en todos los sitios muestreados (Figura 6). Las especies sinantrópicas en conjunto alcanzaron al $21 \%$ del total de las capturas. Los rendimientos de capturas fueron desde 7,5 a $0,5 \%$.

Sólo en dos de los sitios muestreados se registraron roedores seropositivos. El primero de ellos correspondió a un sitio ubicado en el valle central de la región, en que se detectaron 3 $O$.longicaudatus seropositivos. El segundo registro correspondió a dos ejemplares de $A$. longipilis capturados en el Parque Nacional Conguillío. ${ }^{11}$

\section{Región de Los Lagos}

Seis puntos de captura fueron seleccionados en la Región de Los Lagos, tres áreas de cordillera y tres de costa, siguiendo el padrón de presentación de casos en esa zona. Las áreas de cordillera con vegetación principalmente de bosque caducifolio húmedo de Los Andes y bosque laurifolio siempre verde en la costa.

Un total de 329 roedores fueron capturados entre mayo y septiembre de 1998. Seis especies silvestres y 2 sinantrópicas estaban representadas en las capturas. Los rendimientos de capturas variaron desde 3,6 a 24,4\% siendo mayores en las áreas de cordillera en las que predominó A. longipilis. En la región las especies más frecuentemente capturadas fueron A. longipilis
(37\%), A. olivaceus (32\%) y O.longicaudatus (28\%) (Figura 7).

El 1,5\% del total de las capturas de esta región resultó seropositivo para hantavirus. Esto correspondió a un ejemplar de $O$. longicaudatus proveniente de la zona costera de Osorno en que se produjo un caso de SPH y 3 A. longipilis y un $O$. longicaudatus, capturados en el área cordillerana de Valdivia. ${ }^{12}$

\section{Región de Aysén}

En esta región se presentó el mayor brote de casos de SPH. Existen en ella condiciones ambientales propicias para la proliferación de roedores silvestres y asentamientos humanos incorporados a los ambientes naturales, lo que aumenta la probabilidad de contacto entre los reservorios y el hombre. Esta situación motivó a las autoridades regionales a realizar estudios de largo plazo a objeto de conocer la dinámica poblacional de los roedores silvestres de la región en relación a los factores ambientales y su impacto en la prevalencia de hantavirus en estas poblaciones. Así, en 1998 el Servicio Agrícola y Ganadero de esa región inició un estudio longitudinal que considera la instalación de seis estaciones de monitoreo ubicadas sobre un eje que recorre de norte a sur la región y que desde el punto de vista vegetacional corresponde principalmente al llamado bosque caducifolio de la región de Aysén. En las estaciones cuyas ubicaciones coinciden con la presentación de casos de SPH, se realizarán capturas y análisis de roedores cuatro veces al año por un período de tres años.

Durante el primer año del estudio, un total 593 roedores fueron capturados en las seis estaciones. Un aumento de las poblaciones de roedores se evidenció a partir de julio hasta noviembre, siendo la especie $O$. longicaudatus la más abundante en la región. Alcanzó al 55\% de las capturas detectándose su presencia en todas las estaciones de monitoreo. A. olivaceus se encontró en tres sitios y alcanzó el $22 \%$ del total de las capturas y A. longipilis, representado en cuatro sitios de monitoreo, llego al $16 \%$ de las capturas.

Un total de 20 ejemplares resultaron seropositivos a hantavirus lo que representa el $3,4 \%$ del total de las capturas. Cinco de las seis 
estaciones de captura registraron roedores positivos lo que indica la amplia dispersión del virus en la región. De los roedores positivos $55 \%$ correspondían a $O$. longicaudatus, $25 \%$ a A. longipilis, y $20 \%$ A. olivaceus. ${ }^{13}$

\section{Conocimientos de la epidemiología del hantavirus en Chile a partir de los estudios de reservorio}

Los estudios de reservorios realizados hasta ahora en Chile han permitido contar con importante información que contribuye a conocer de mejor forma la epidemiología del hantavirus aunque es preciso no perder de vista que, parte de la información obtenida, plantea interrogantes que requieren ser aclaradas.

Los antecedentes recabados a partir de las investigaciones de terreno hasta ahora realizadas permiten afirmar que en el país, al igual que en el sur de Argentina, el ratón colilargo ( $O$. longicaudatus), es el reservorio del hantavirus variedad Andes. Por otra parte, queda en evidencia que existe circulación de hantavirus en todas las regiones, en distintos hábitats en los que se han realizado estudios de reservorio y en que se encuentra presente esta especie.

Si bien $O$. longicaudatus se encuentra distribuido en todo el área estudiada, parece claro que sus poblaciones registran mayores densidades a medida que se desplazan hacia la zona sur. Esta situación se explicaría por la afinidad de esta especie a ambientes naturales menos intervenidos, con mayor abundancia de vegetación autóctona y mayor humedad, propios de la zona sur.

De los análisis serológicos practicados a los roedores capturados en los estudios realizados, se han detectado ejemplares de cinco especies de múridos silvestres que presentan anticuerpos para hantavirus. De acuerdo a los conocimientos actuales de esta zoonosis, este hallazgo no significa necesariamente que todas estas especies sean reservorios efectivos del virus, dado que como han demostrado investigaciones internacionales, es común que a partir del reservorio se produzcan infecciones en individuos de otra especies, generando en éstos respuestas inmunológicas que explican su seropositividad. Sin embargo, en los individuos así infectados, el virus es eliminado por el sistema inmune, por lo que éstos no son portadores y no tiene la capacidad de excretarlo.

Por otra parte, de acuerdo a las investigaciones realizadas en el ISP de Chile, tendientes a establecer la presencia de virus en los roedores identificados como seropositivos en los estudios regionales, se ha detectado presencia de virus, por la técnica de TR-RPC (RT-PCR), en ocho O. longicaudatus y dos A. longipilis. Estos resultados confirman la calidad de portador del ratón colilargo, y abren la interrogante sobre la calidad de tal de A. longipilis.

Estudios posteriores se requerirán para determinar si la recuperación de virus a partir de tejidos de A. longipilis se debe a que los individuos fueron muestreados en las etapas primarias de una infección por derrame del virus desde su reservorio natural, o si es portador efectivo del virus. Estas investigaciones deberán establecer además, si A. longipilis es portador del virus Andes, o si es portador de una variante de hantavirus diferente a ésta, lo que parecería más probable considerando la especificidad interespecie demostrada por los hantavirus hasta ahora conocidos.

\section{RESUMEN}

El primer caso de síndrome pulmonar por hantavirus ( $\mathrm{SPH})$ registrado en Chile determinó la necesidad de desarrollar investigaciones en las poblaciones de roedores tendientes a identificar el reservorio de hantavirus en Chile, su distribución y hábitat, así como la distribución del hantavirus dentro de las poblaciones del reservorio.

Entre 1996 y 1999 se desarrollaron estudios de reservorios desde la Región Metropolitana a la Región de Aysén. El aislamiento del virus variedad Andes, a partir del Oligorizomys longicaudatus, permite afirmar que, al igual que en la zona sur de Argentina, éste es el reservorio de hantavirus en Chile. La especie Abrothrix longipilis también resulto positiva al aislamiento viral, por lo que estudios posteriores deberán determinar si éste es otro reservorio del virus en el país. Otras tres especies de roedores silvestres resultaron seropositivas al virus lo que se explicaría como una infección transitoria a 
partir del reservorio.

Se pudo constatar la presencia del reservorio en todas las regiones muestreadas, aunque las densidades poblacionales de esta especie son mayores en la zona sur. Existe circulación de hantavirus en toda el área de distribución del reservorio.

\section{BIBLIOGRAFIA}

1.- WANG LEE H, VAN DER GROEN G. Hemorragic Fever with Renal Syndrome. Prog Med Virol 1989; 36: 62-102.

2.- WELLS R, YOUNG L, WILLIAMS $\mathrm{J}$ et al. Hantavirus transmission in the United States. Emerg Infect Dis 1997; 13 (3): 361-4.

3.- WELLS R, SOSA S, YADON Z et al. An unusual Hantavirus outbreak in Southern Argentina: Person to person transmission?. Emerg Infect Dis 1997; 13 (2): $171-4$.

4.- MUÑOZ-PEDREROS A. Orden Rodentia. MuñozPedreros A, Yañez J, Mamíferos de Chile, Temuco, Ediciones CEA, 2000; 73-126.

5.- MILLS J, KSIAZEKT, ELLIS B et al. Patterns of association with host and habitat: Antibody reactive with Sin Nombre Virus in small mammals in the major biotic communities of the Southwestern United States. Am J Trop Med Hyg 1997; 56 (3): 273-84.

6.- MURUA R. Estudio Reservorios Hantavirus X Región, 1996, Informe Final. Instituto de Ecología y Evolución, Universidad Austral de Chile, Servicio de Salud Osorno.

7.- Hantavirus Pulmonary Syndrome, Chile, 1997. MMWR 1997; 46: 40.

8.- CATTAN P. Estudio de reservorios de Hanta Virus en la Región Metropolitana, 1998, Informe Final. Facultad de Ciencias Veterinarias y Pecuarias, Universidad de Chile, Servicio de Salud del Ambiente Región Metropolitana.

9.- CATTAN P. Estudio de reservorios de Hanta Virus en la localidad de Picarquin, VI Región, 1998, Informe Final. Facultad de Ciencias Veterinarias y Pecuarias, Universidad de Chile, Servicio de Salud O'Higgins.

10.- ORTIZ J C, VENEGAS W. Estudio e identificación de las especies de roedores silvestres reservorios del Virus Hanta en la Región del Bío Bío, 1998, Informe Final. Universidad de Concepción, Secretaria Regional Ministerial de Salud, Región del Bío Bío.

11.- MUÑOZ-PEDREROS A. Estudio de roedores reservorios de Virus Hanta Región de la Araucania, 1998-1999. Informe final (en prensa). Universidad Católica de Temuco, Servicio de Salud Araucania Sur.

12.- MURUA R. Estudio reservorios Hantavirus X Región, 1998, Informe final. Instituto de Ecología y Evolución, Universidad Austral de Chile, Servicio de Salud Valdivia.

13.- CERDA J et al. Monitoreo de roedores silvestres en seis localidades rurales de la Región de Aysén, Informe final 1998. Servicio Agrícola y Ganadero, Región de Aysén, Servicio de Salud de Aysén, Gobierno Regional de Aysén.

Correspondencia a:

Carlos Pavletic Brevis

Fax. 56(2): 6397110

Email:cpavletic@netline.cl 